\title{
First retrieval of tropospheric aerosol profiles using MAX-DOAS and comparison with lidar and sky radiometer measurements
}

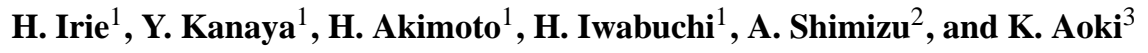 \\ ${ }^{1}$ Frontier Research Center for Global Change, Japan Agency for Marine-Earth Science and Technology, 3173-25 \\ Showa-machi, Kanazawa-ku, Yokohama, Kanagawa 236-0001, Japan \\ ${ }^{2}$ National Institute for Environmental Studies, 16-2, Onogawa, Tsukuba, Ibaraki 305-8506, Japan \\ ${ }^{3}$ Department of Earth Science, Faculty of Sciences, University of Toyama, 3190 Gofuku, Toyama 930-8555, Japan
}

Received: 30 May 2007 - Published in Atmos. Chem. Phys. Discuss.: 5 July 2007

Revised: 12 October 2007 - Accepted: 5 December 2007 - Published: 28 January 2008

\begin{abstract}
Ground-based Multi-Axis Differential Optical Absorption Spectroscopy (MAX-DOAS) measurements were performed at Tsukuba, Japan $\left(36.1^{\circ} \mathrm{N}, 140.1^{\circ} \mathrm{E}\right)$, in November-December 2006. By analyzing the measured spectra of scattered sunlight with DOAS and optimal estimation methods, we first retrieve the aerosol optical depth $(\tau)$ and the vertical profile of the aerosol extinction coefficient $(k)$ at $476 \mathrm{~nm}$ in the lower troposphere. These retrieved quantities are characterized through comparisons with coincident lidar and sky radiometer measurements. The retrieved $k$ values for layers of $0-1$ and $1-2 \mathrm{~km}$ agree with lidar data to within $30 \%$ and $60 \%$, respectively, for most cases, including partly cloudy conditions. Results similar to $k$ at $0-1 \mathrm{~km}$ are obtained for the retrieved $\tau$ values, demonstrating that MAX-DOAS provides a new, unique aerosol dataset in the lower troposphere.
\end{abstract}

\section{Introduction}

Atmospheric aerosols reflect and absorb solar radiation and modify cloud properties, altering the Earth's radiation balance and hence climate. A major uncertainty in the prediction of future climate change arises from the difficulty of modeling the effects of atmospheric aerosols. Because aerosols impact both regional and global energy budgets, owing to their highly non-uniform spatial and temporal distributions in the troposphere, a multiple-measurement approach is highly desirable to assess their impacts on the Earth's system (Kaufman et al., 2002).

Recently, the ground-based Multi-Axis Differential Optical Absorption Spectroscopy (MAX-DOAS) technique has been proposed as a new technique to measure aerosol optical properties in the troposphere (Wagner et al., 2004; Frieß

Correspondence to: $\mathrm{H}$. Irie

(irie@jamstec.go.jp) et al., 2006). The measurements can be performed with a relatively simple setup and very low power consumption. The optical properties that are potentially measurable by MAX-DOAS include the aerosol optical depth $(\tau)$ as well as the vertical profile of the aerosol extinction coefficient $(k)$, while the well-established Sun photometer measurement technique can only retrieve optical properties of the total atmospheric column. The MAX-DOAS technique basically utilizes the differential absorption structures of the oxygen collision complex $\left(\mathrm{O}_{2}-\mathrm{O}_{2}\right.$ or $\left.\mathrm{O}_{4}\right)$ in the visible wavelength region to derive aerosol information. Because no absolute radiometric calibrations are generally needed, MAX-DOAS is suitable for conducting long-term automated measurements in a consistent manner, even at remote sites. In addition, MAX-DOAS measurements can yield significant information about several important trace gases, such as nitrogen dioxide $\left(\mathrm{NO}_{2}\right)$, formaldehyde, and glyoxal (e.g., Hönninger et al., 2004; Wittrock et al., 2004; Heckel et al., 2005; Hendrick et al., 2006; Leigh et al., 2006; Sinreich et al., 2007), and thus have a variety of potential applications for understanding the Earth's system. Necessary input parameters for trace gas retrievals are given by the derived aerosol properties. However, no MAX-DOAS aerosol measurements for the real atmosphere have been reported in the literature.

We performed ground-based MAX-DOAS measurements at Tsukuba, Japan $\left(36.1^{\circ} \mathrm{N}, 140.1^{\circ} \mathrm{E}, 29 \mathrm{~m}\right.$ a.s.l. $)$, from 1 November to 21 December 2006. Here we present, for the first time, the retrieval algorithm for determining $\tau$ and the vertical profile of $k$ at a wavelength $(\lambda)$ of $476 \mathrm{~nm}$. The wavelength of $476 \mathrm{~nm}$ corresponds to the $\mathrm{O}_{4}$-cross-sectionweighted mean wavelength over the fitting window chosen for the spectral fitting (460-490 nm). We next show comparisons with lidar and sky radiometer measurements conducted at the same site. Although the geometry and the integration time for completing a set of MAX-DOAS measurements are different from those of the lidar and sky radiometer, we attempt to estimate the overall uncertainty of the retrieved $k$

Published by Copernicus Publications on behalf of the European Geosciences Union. 


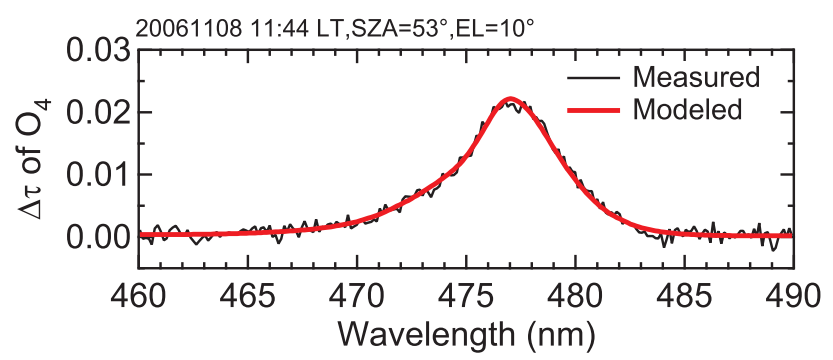

Fig. 1. Example of nonlinear least-squares spectral fitting results for $\mathrm{O}_{4}$. This is for $\mathrm{SZA}=53^{\circ}$ and $\mathrm{EL}=10^{\circ}$ on 8 November 2006. The red line shows the cross section scaled to the measured spectrum (black) by the DOAS technique. The spectra are plotted as a differential optical density $(\Delta \tau)$ from the reference spectrum $\left(\mathrm{EL}=90^{\circ}\right)$.

values for layers of $0-1$ and $1-2 \mathrm{~km}$, to which the sensitivity of MAX-DOAS measurements has been simulated to be much higher than at other altitudes (Frieß et al., 2006). Limitations in the retrieval of $\tau$ are discussed based on the comparisons with sky radiometer and lidar data.

\section{Measurement and Retrieval Algorithm}

\subsection{MAX-DOAS}

Our MAX-DOAS instrument consists of two main parts: a telescope unit placed outdoors and a miniaturized UV/visible spectrometer (B\&W TEK Inc., BTC111) indoors. These are connected via a $3-\mathrm{m}$ fiber-optic bundle cable consisting of seven cores, each of which having a diameter of $100 \mu \mathrm{m}$. The telescope unit has two viewing quartz windows, one for the zenith and one for off-axis directions. The line of sight for off-axis geometries was directed northwest. A movable mirror on a rotary actuator was installed inside the telescope unit, allowing a sequential measurement of scattered sunlight at six different elevation angles (ELs) of $3^{\circ}, 5^{\circ}, 10^{\circ}$, $20^{\circ}, 30^{\circ}$, and $90^{\circ}$ every $30 \mathrm{~min}$. A plano-convex lens (focal length $=40 \mathrm{~mm}$ and diameter $=25 \mathrm{~mm}$ ) focuses the received sunlight onto the fiber. The field of view (FOV) was estimated to be $<1^{\circ}$. The spectrometer employs a $10-\mu \mathrm{m}$ width slit, a Crossed Czerny-Turner optical layout, a plane-ruled grating with a groove frequency of 1800 lines $\mathrm{mm}^{-1}$ at a blaze wavelength of $250 \mathrm{~nm}$, a thermoelectrically cooled linear charge-coupled device (CCD) array (ILX511, Sony) with 2048 elements covering a wavelength region of $283-566 \mathrm{~nm}$, and a built-in 16-bit digitizer with a high-speed USB interface.

For the measured spectra, the wavelength calibration was performed by fitting a high-resolution solar spectrum $(\mathrm{Ku}-$ rucz et al., 1984) to the spectra measured with our instrument. The instrument slit function was assumed to be a Gaussian shape, based on measurements of mercury emission lines around 404.7, 407.8, and $435.8 \mathrm{~nm}$. The wave-

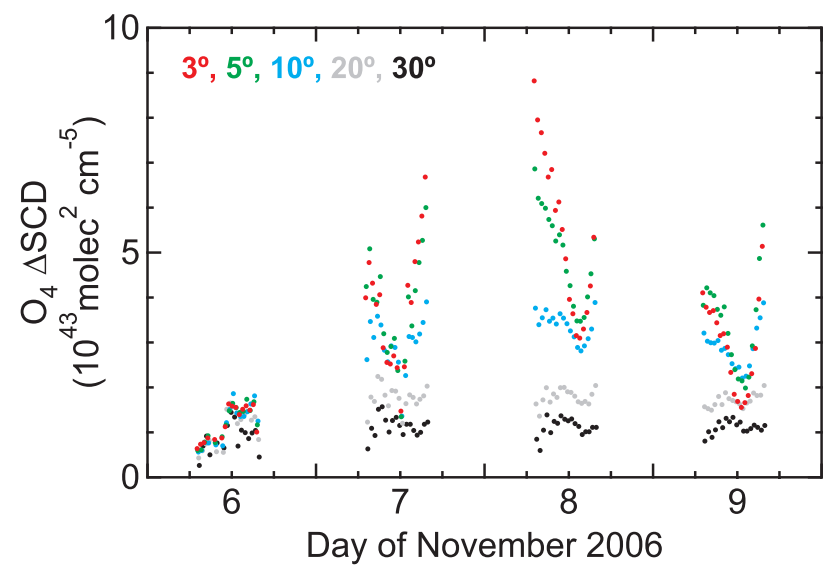

Fig. 2. Time series of $\mathrm{O}_{4} \Delta \mathrm{SCD}$ values at $\mathrm{EL}=3^{\circ}$ (red), $5^{\circ}$ (green), $10^{\circ}$ (blue), $20^{\circ}$ (gray), and 30 (black) on 6-9 November 2006.

length calibration was made daily to take into account temporal changes of wavelength shift and spectral resolution. For the wavelength region analyzed $(460-490 \mathrm{~nm})$, the spectral resolution (Full Width at Half Maximum (FWHM)) was about $0.55 \mathrm{~nm}$.

The retrieval algorithm for deriving aerosol information was a 2-step procedure. First, the measured spectra of scattered sunlight at $460-490 \mathrm{~nm}$ were analyzed based on the so-called DOAS technique (Platt, 1994) using the nonlinear least-squares spectral fitting method (Levenberg-Marquardt method Rodgers, 2000) to retrieve the differential slant column density $(\triangle \mathrm{SCD})$ of $\mathrm{O}_{4}$. This spectral fitting was performed with the logarithm of the intensity $(\ln I(\lambda))$ :

$$
\ln I(\lambda)=\ln \left(I_{0}(\lambda)-c(\lambda)\right)-\sum_{i=1}^{n} \sigma_{i}(\lambda) \Delta \mathrm{SCD}_{i}-p(\lambda),
$$

where the $\triangle \mathrm{SCD}$ is defined as the difference between the slant column density along the path of sunlight for an offaxis measurement $\left(\mathrm{EL}<90^{\circ}\right)$ and that for a zenith-sky measurement $\left(\mathrm{EL}=90^{\circ}\right) . I_{0}(\lambda)$ is the reference spectrum at time $t$, which was derived by interpolating two spectra measured at $\mathrm{EL}=90^{\circ}$ within $30 \mathrm{~min}$ before and after the offaxis measurement was made at $t$. Over $460-490 \mathrm{~nm}$, a wavelength-dependent offset, $c(\lambda)$, and a slowly-changing structure mainly due to Rayleigh and Mie scattering, $p(\lambda)$, were taken into account by 2 nd- and 3rd-order polynomials, respectively. The gas species considered were $\mathrm{O}_{4}, \mathrm{NO}_{2}$, $\mathrm{O}_{3}$, and $\mathrm{H}_{2} \mathrm{O}$, for which we adopted absorption cross section $(\sigma)$ data of Greenblatt et al. (1990) (with manual adjustment (A. Richter, personal communication)), Vandaele et al. (1998); Bogumil et al. (2003), and the year 2000 edition of the High-Resolution Transmission (HITRAN) database (Rothman et al., 2003), respectively. In addition, we took into account the Ring effect (Grainger and Ring, 1962) and the undersampling effect using the model of Chance and Spurr (1997) and the method of Chance et al. (2005), 
respectively. The so-called $\mathrm{I}_{0}$ effect, arising due to different conditions (spectral resolution and light source) under which laboratory experiments of absorption cross sections and atmospheric measurements were made, was considered for all the absorption cross section data, according to the method of Aliwell et al. (2002).

An example of the DOAS spectral fitting results is shown in Fig. 1, where two spectra of the $\mathrm{O}_{4}$ differential optical density $(\Delta \tau)$, which correspond to the scaled cross section (red), $\sigma \triangle \mathrm{SCD}$, and the sum of the scaled cross section and the residual (black), respectively, are plotted. The median residual of $\Delta \tau$ for all the measurements around noon (solar zenith angle $(\mathrm{SZA})=50^{\circ} \pm 5^{\circ}$ ) was as small as $6 \times 10^{-4}$. The corresponding $\mathrm{O}_{4} \triangle \mathrm{SCD}$ error was $\sim 1 \times 10^{41}$ molecules $^{2} \mathrm{~cm}^{-5}$, according to the two types of estimates using the measurement covariance matrix constructed based on the statistics of dark counts in nighttime and that constructed from the residuals. For 6-9 November 2006, the retrieved $\mathrm{O}_{4} \Delta \mathrm{SCD}$ values are shown in Fig. 2. On 6 November, cloud bases were persistently detected at altitudes of 3-6 km by lidar over Tsukuba, whereas on 7-9 November the sky was relatively clear. Consistent with the fact that aerosols/clouds lower $\triangle \mathrm{SCD}$ by shortening the effective path of sunlight reaching the telescope (Wagner et al., 2004), $\triangle$ SCD data on 6 November show smaller values and weaker dependences on EL. These indicate that $\triangle \mathrm{SCD}$ values were retrieved precisely from our instrumentation and analyses. From 6 to 9 November, a significant temporal variation of aerosols in the lower troposphere is expected to have occurred as $\triangle \mathrm{SCD}$ values varied over the time period (Fig. 2).

We next used the following methods to convert the $\mathrm{O}_{4} \Delta \mathrm{SCD}$ values into $\tau$ and the vertical profile of $k$ at $\lambda=476 \mathrm{~nm}$. We defined the measurement vector $(y$; representing quantities to be fitted) and the state vector ( $x$; representing quantities to be retrieved) as

$\mathbf{y}=\left(\mathrm{O}_{4} \Delta \operatorname{SCD}\left(\boldsymbol{\Omega}_{1}\right) \cdots \mathrm{O}_{4} \Delta \mathrm{SCD}\left(\boldsymbol{\Omega}_{n}\right)\right)^{T}$

$\mathbf{x}=\left(\tau F_{1} F_{2} F_{3}\right)^{T}$,

respectively, where $n$ is the number of measurements in a 30-min interval, which corresponds to a complete sequence of ELs, and $\Omega$ is the observation geometry vector consisting of three components: the solar zenith angle (SZA), the relative azimuth angle (RAA), and EL. RAA is the azimuth angle between the telescope direction and the Sun. $F$ values are the parameters determining the shape of a vertical profile and are defined to range between 0 and 1 . Thereby, partial $\tau$ values for $0-1,1-2$, and $2-3 \mathrm{~km}$ can be described as $\tau F_{1}$, $\tau\left(1-F_{1}\right) F_{2}$, and $\tau\left(1-F_{1}\right)\left(1-F_{2}\right) F_{3}$, respectively, and the partial $\tau$ above $3 \mathrm{~km}$ as $\tau\left(1-F_{1}\right)\left(1-F_{2}\right)\left(1-F_{3}\right)$.

From the given partial $\tau$ above $3 \mathrm{~km}$, we determined the profile of $k$ for a layer from 3 to $100 \mathrm{~km}$ assuming a $k$ value at the top of the layer $(100 \mathrm{~km})$ and an exponential profile shape. Similarly, we determined profiles for layers of 2-3, $1-2$, and $0-1 \mathrm{~km}$, completing the $k$ vertical profile from the

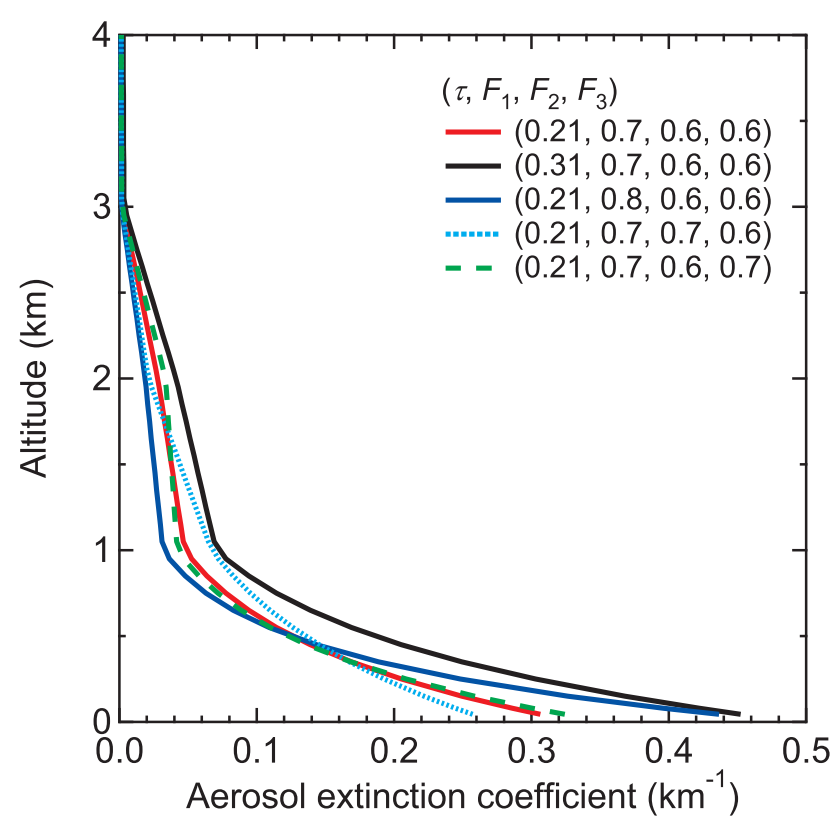

Fig. 3. Examples of the vertical profile of the aerosol extinction coefficient represented by four parameters $\tau, F_{1}, F_{2}$, and $F_{3}$.

surface to $100 \mathrm{~km}$. To represent a $k$ profile with the above method, the prerequisite $k$ value at $100 \mathrm{~km}$ was obtained by extrapolating Stratospheric Aerosol and Gas Experiment III (SAGE III) $k$ data $(\lambda=448$ and $521 \mathrm{~nm}$ ) taken at altitudes of $15-40 \mathrm{~km}$. Although this estimate might be crude, this assumption for high altitudes does not significantly influence the retrieval for the lower troposphere (Frieß et al., 2006). In support of this, a sensitivity test conducted using a tenfold $k$ value for $100 \mathrm{~km}$ showed that its impact on the retrievals of $\tau$ and $k$ below $2 \mathrm{~km}$ was less than $3 \%$ (Table 1).

Although a $k$ profile is represented by only four parameters, we can obtain various continuous profiles, as shown in Fig. 3. Moreover, the parameterization has an advantage that the retrieval can be made without a priori knowledge of the absolute value of $k$; Frie $\beta$ et al. (2006) have argued that using inappropriate a priori constrains on $k$ can easily cause unrealistic or strongly biased results. We instead used a priori information of the profile shape, which is parameterized by the $F$ values, because the relative variability of the profile shape, in terms of $1-\mathrm{km}$ averages, was much less than that of the absolute $k$ value for the period and time of the measurements presented here, as mentioned below. There are, however, disadvantages in that it is not easy to directly derive the vertical resolution and the measurement sensitivity. We will attempt to derive them from the comparisons with lidar and sky radiometer measurements below.

For different sets of aerosol profiles and observation geometries, we created a lookup table (LUT) of the box-airmass-factor $\left(A_{\text {box }}\right)$ vertical profile using our radiative transfer model, the Monte Carlo Atmospheric Radiative Transfer 


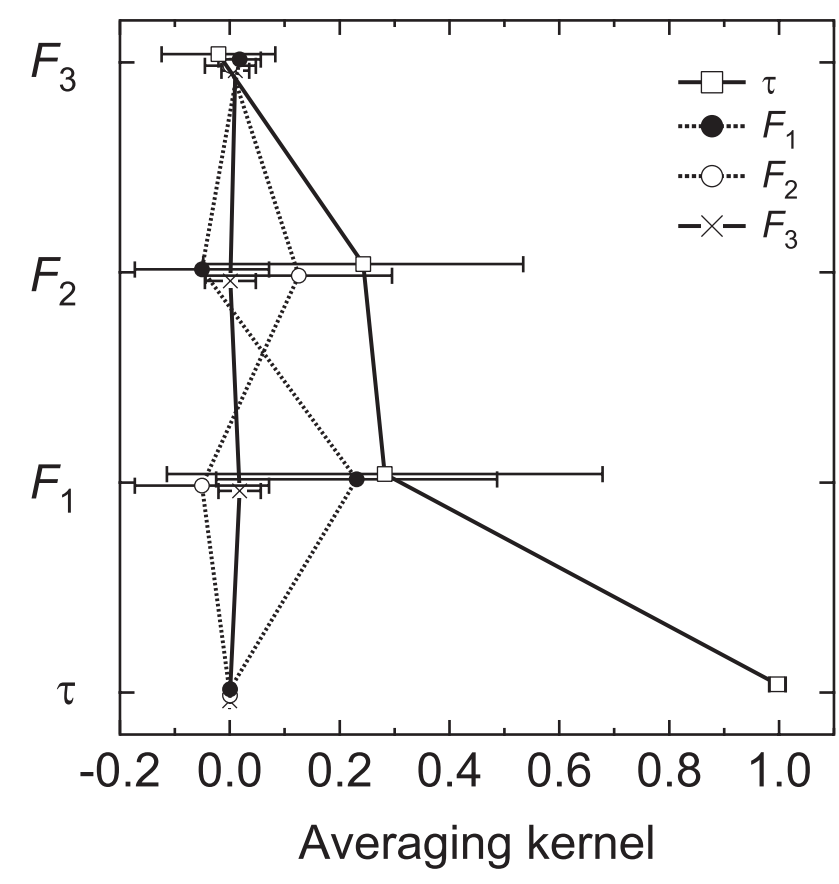

Fig. 4. Mean averaging kernels for all the MAX-DOAS aerosol retrievals. Error bars represent $1 \sigma$ standard deviations.

Simulator (MCARaTS) (Iwabuchi, 2006). MCARaTS is a parallelized three-dimensional radiative transfer model utilizing the forward-propagating Monte Carlo photon transport algorithm. Radiances are calculated by integrating the contributions from each event of scattering or source emission, according to the local estimation method (Marchuk et al., 1980). For a given layer, the $A_{\text {box }}$, which characterizes the ratio of partial slant to vertical columns, is obtained as an intensity-weighted average path length. Highprecision calculations of the $A_{\text {box }}$ profiles are made by simulating $10^{6}$ photons. The collision-forcing method of Iwabuchi (2006) is used to reduce the computational noise in the cases of optically-thin atmosphere. The $A_{\text {box }}$ calculations by MCARaTS have been validated through comparisons with other radiative transfer models (Wagner et al., 2007). To simulate a realistic atmosphere, we considered the surface altitude at the measurement site and the altitude where the instrument was located (about $30 \mathrm{~m}$ above the surface). The present LUT contains more than $300000 A_{\text {box }}$ profiles in 7 dimensions of $\tau, F_{1}, F_{2}, F_{3}$, SZA, RAA, and EL. Each profile has 72 layers for altitudes up to $100 \mathrm{~km}$, with a layer thickness of $100 \mathrm{~m}$ at altitudes below $5.1 \mathrm{~km}$. We assumed single values of the single scattering albedo $(s=0.95)$, the asymmetry parameter ( $g=0.65$, under the Henyey-Greenstein approximation), and the surface albedo $(a=0.10)$. The sensitivities of all the retrievals (both $\tau$ and $k$ values below $2 \mathrm{~km}$ ) to changing these parameters $(g, s$, and $a)$ by \pm 0.05 were estimated to be less than $8 \%, 1 \%$, and $2 \%$, respectively (Table 1).
For off-axis measurement geometries, we also created a LUT for profiles of $\Delta A_{\text {box }}$, which was calculated by subtracting the corresponding zenith-sky $A_{\text {box }}$ value. Instead of $A_{\text {box }}$, the $\Delta A_{\text {box }}$ value was used in the retrieval, as it is more directly linked to $\triangle \mathrm{SCD}$.

Under the above setup conditions, the $\tau$ value and $k$ profile were retrieved by applying the optimal estimation method (Rodgers, 2000). The nonlinear inversion problem was solved using the iteration equation:

$$
\begin{gathered}
\boldsymbol{x}_{i+1}=\boldsymbol{x}_{i}+\left(\boldsymbol{S}_{a}^{-1}+\boldsymbol{K}_{i}^{T} \boldsymbol{S}_{\varepsilon}^{-1} \boldsymbol{K}_{i}+\gamma_{i} \boldsymbol{D}\right)^{-1} \\
\left\{\boldsymbol{K}_{i}^{T} \boldsymbol{S}_{\varepsilon}^{-1}\left[\boldsymbol{y}-\boldsymbol{F}\left(\boldsymbol{x}_{i}\right)\right]-\boldsymbol{S}_{a}^{-1}\left[\boldsymbol{x}_{i}-\boldsymbol{x}_{a}\right]\right\}
\end{gathered}
$$

where $\mathbf{x}_{i+1}$ and $\mathbf{x}_{i}$ are the current and previous state vectors, respectively. $\mathbf{S}_{\varepsilon}$ is the measurement error covariance matrix, $\mathbf{K}_{i}$ is the weighting function matrix, and $\mathbf{F}$ represents the forward model converting a given aerosol profile to $\mathrm{O}_{4} \Delta \mathrm{SCD}$ values. $\mathbf{D}$ is the diagonal scaling matrix and $\gamma_{i}$ is the parameter updated in each iteration to optimize the retrieval. The a priori state vector $\left(\mathbf{x}_{a}\right)$ and the a priori covariance matrix $\left(\mathbf{S}_{a}\right)$ were constructed based on averages and standard deviations (s.d.) of two months of lidar data, mentioned below. The a priori values ( \pm error) used were $\tau=0.21 \pm 1.0$, $F_{1}=0.70 \pm 0.05, \quad F_{2}=0.60 \pm 0.05$, and $F_{3}=0.60 \pm 0.05$, yielding a $\tau$ of $0.21, k(0-1 \mathrm{~km})$, defined as the mean $k$ for 0 $1 \mathrm{~km}$, of $0.15 \mathrm{~km}^{-1}, k(1-2 \mathrm{~km})$ of $0.04 \mathrm{~km}^{-1}$, and $k(2-3 \mathrm{~km})$ of $0.02 \mathrm{~km}^{-1}$. The errors are $\pm 1.0,+0.76 /-0.66 \mathrm{~km}^{-1}$, $+0.23 /-0.15 \mathrm{~km}^{-1}$, and $+0.11 /-0.05 \mathrm{~km}^{-1}$, respectively. Thus, the relative error (variation) ranges of the $F$ values are much smaller than those of the absolute $k$ values. The above a priori errors correspond to $20 \%$ of the s.d. of $F$ values from the lidar data, but three times that of $\tau$. This modification was made to stabilize the retrieval and allow for a wide range of values. Non-diagonal elements of the a priori covariance matrix were set to zero. Results from the sensitivity studies of the a priori values and their errors are summarized in Table 1. In the tested ranges, the impacts on $\tau, k(0-1 \mathrm{~km})$, and $k(1-$ $2 \mathrm{~km}$ ) values were less than $6 \%, 5 \%$, and $31 \%$, respectively.

Figure 4 shows the mean averaging kernels for all the MAX-DOAS aerosol retrievals. Except for $F_{3}$, the peaks of the averaging kernels are located at the corresponding variable. $\tau$ indicates the largest value, followed by $F_{1}$ and $F_{2}$, suggesting a higher sensitivity of MAX-DOAS measurements to lower-altitude aerosols. The resulting degrees of freedom for signal (Rodgers, 2000) ranged from 1.0 to 2.7 for the whole period. The area (Rodgers, 2000), which provides a rough measure of the fraction of the retrieval that comes from the measurements, was calculated as the sum of all elements in the averaging kernel profile weighted by the a priori error (Liu et al., 2005). The areas were 1.0, 0.2, 0.1, and 0.1 for $\tau, F_{1}, F_{2}$, and $F_{3}$, respectively, indicating that the retrieval was done by scaling the given a priori profile first, followed by changing the profile shape. The $\mathrm{O}_{4} \Delta \mathrm{SCD}$ values modeled under these conditions (Fig. 5) agreed well 
Table 1. Median Absolute (Relative) Errors Estimated From Sensitivity Tests and the Retrieval Covariance Matrix.

\begin{tabular}{llrrr}
\hline Error Source & Test & $\begin{array}{r}k(0-1 \mathrm{~km}) \\
\left(\mathrm{km}^{-1}\right)\end{array}$ & $\begin{array}{r}k(1-2 \mathrm{~km}) \\
\left(\mathrm{km}^{-1}\right)\end{array}$ \\
\hline Fixed $k$ at $100 \mathrm{~km}$ & Tenfold & $<0.01(3 \%)$ & $<0.01(3 \%)$ & $<0.01(2 \%)$ \\
Fixed asymmetry para. & \pm 0.05 & $0.01(6 \%)$ & $0.01(7 \%)$ & $<0.01(8 \%)$ \\
Fixed single scat. albedo & \pm 0.05 & $<0.01(<1 \%)$ & $<0.01(<1 \%)$ & $<0.01(<1 \%)$ \\
Fixed surface albedo & \pm 0.05 & $<0.01(2 \%)$ & $<0.01(2 \%)$ & $<0.01(1 \%)$ \\
A priori $\tau$ & \pm 0.1 & $<0.01(<1 \%)$ & $<0.01(<1 \%)$ & $<0.01(<1 \%)$ \\
A priori $F_{1}$ & \pm 0.1 & $0.01(4 \%)$ & $<0.01(5 \%)$ & $0.01(31 \%)$ \\
A priori $F_{2}$ & \pm 0.1 & $0.02(6 \%)$ & $<0.01(5 \%)$ & $<0.01(5 \%)$ \\
A priori $F_{3}$ & \pm 0.1 & $<0.01(<1 \%)$ & $<0.01(<1 \%)$ & $<0.01(<1 \%)$ \\
A priori $\tau$ error & \pm 0.1 & $<0.01(<1 \%)$ & $<0.01(<1 \%)$ & $<0.01(<1 \%)$ \\
A priori $F_{1}$ error & \pm 0.01 & $<0.01(<1 \%)$ & $<0.01(<1 \%)$ & $<0.01(<1 \%)$ \\
A priori $F_{2}$ error & \pm 0.01 & $<0.01(<1 \%)$ & $<0.01(<1 \%)$ & $<0.01(<1 \%)$ \\
A priori $F_{3}$ error & \pm 0.01 & $<0.01(<1 \%)$ & $<0.01(<1 \%)$ & $<0.01(<1 \%)$ \\
Smoothing and retrieval & - & $0.01(7 \%)$ & $0.02(14 \%)$ & $0.01(30 \%)$ \\
noise errors & & & & \\
Overall error & - & $0.03(12 \%)$ & $0.02(18 \%)$ & $0.01(44 \%)$ \\
\hline
\end{tabular}

with those measured (Fig. 2). For each 30-min interval, the relative residual, (residual of $\left.\mathrm{O}_{4} \Delta \mathrm{SCD}\right) /($ mean measured $\mathrm{O}_{4} \Delta \mathrm{SCD}$ ), was calculated. The median of the relative residuals for all the retrievals was $9 \%$.

The error of the retrieved state vector is quantified by the retrieval covariance matrix,

$\hat{\mathbf{S}}=\left(\mathbf{K}^{T} \boldsymbol{S}_{\varepsilon}^{-1} \mathbf{K}+\mathbf{S}_{a}^{-1}\right)$

which is defined to represent the sum of the smoothing error and the retrieval noise error (Rodgers, 2000). For this error estimate, the measurement error covariance matrix $\mathbf{S}_{\varepsilon}$ was constructed from the residual of $\mathrm{O}_{4} \Delta \mathrm{SCD}$, because it was much larger than the $\mathrm{O}_{4} \Delta \mathrm{SCD}$ errors. For all the retrievals, medians of the errors estimated from each of the sensitivity tests conducted above and the retrieval covariance matrix are summarized in Table 1. Overall errors, calculated as the root-sum-squares of these errors, were $0.03(12 \%)$, $0.02 \mathrm{~km}^{-1}(18 \%)$, and $0.01 \mathrm{~km}^{-1}(44 \%)$ for $\tau, k(0-1 \mathrm{~km})$, and $k(1-2 \mathrm{~km})$, respectively (Table 1$)$.

It should be noted that outputs from the retrieval are available only for retrieved $\tau$ less than 3 , the largest value in the LUTs. This excludes considerably large optical depth cases, most of which should be due to optically thick clouds. Further data screening was made using the relative residual, which was a good measure for screening retrievals that yielded a $k$ profile too far from the true profile. This deviation likely happened when the above-mentioned method constructing a profile was too simple to represent the true profile, particularly with a steep vertical gradient of $k$ due to clouds. From all the retrievals, the threshold for this data screening was determined statistically to be $20 \%$, which corresponded

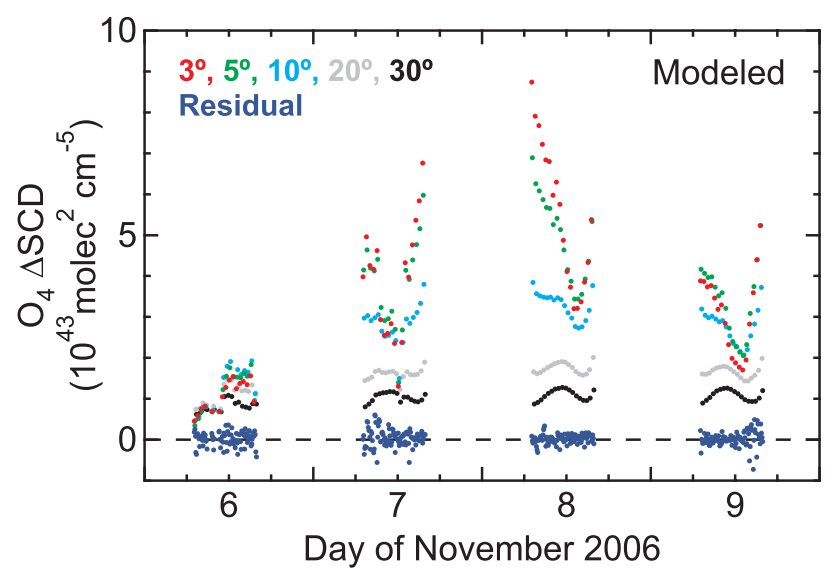

Fig. 5. Same as Fig. 2, but for the modeled $\mathrm{O}_{4} \Delta \mathrm{SCD}$ values. The residuals (modeled minus measured values) are also shown.

to (the mode) plus (the one-sigma width) in a histogram of the relative residuals on a logarithm basis.

\subsection{Lidar}

The lidar system used here was a compact Mie-scattering system utilizing the second harmonics of a flashlamppumped Nd:YAG laser $(532 \mathrm{~nm})$ as a light source (Shimizu et al., 2004). One aerosol profile comprising 3000 shots was obtained in $5 \mathrm{~min}$ followed by a 10 -min rest to extend the laser life. The lidar equation was solved using the inversion method described by Fernald (1984) to derive vertical profiles of aerosol optical properties, such as $k$, with a vertical resolution of $30 \mathrm{~m}$. In the method used here, a constant 


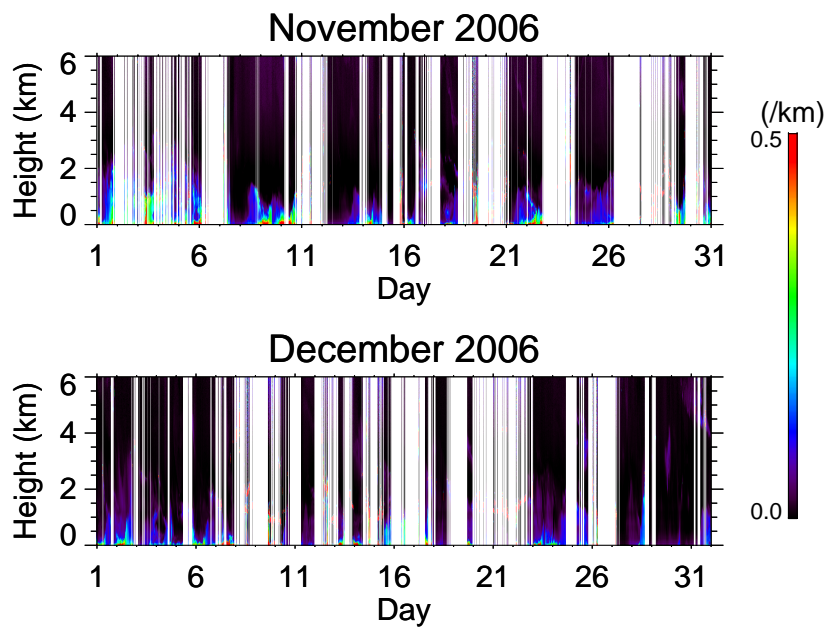

Fig. 6. Vertical profiles of the lidar aerosol extinction coefficient data at $532 \mathrm{~nm}$ for (top) November and (bottom) December 2006.

extinction-to-backscattering ratio $(S)$ of $50 \mathrm{sr}$ was assumed. According to the estimates by previous studies for Aerosol Robotic Network (AERONET) locations and Tsukuba (Cattrall et al., 2005; Tatarov et al., 2006), the $S$ ratio can vary by more than $30 \%$, with resulting errors in $k$ due to the use of a fixed $S$ value occasionally exceeding $30 \%$. Only $k$ data for which no clouds at $0-6 \mathrm{~km}$ were judged by the method of Shimizu et al. (2004) were used below. For reference, vertical profiles of $k$ at $532 \mathrm{~nm}$ measured by the lidar are shown in Fig. 6. We converted the lidar $k$ values at $532 \mathrm{~nm}$ to the values at $476 \mathrm{~nm}$ using Ångström exponent data obtained from the sky radiometer measurements described below.

\subsection{Sky radiometer}

The sky radiometer measured the direct solar irradiance and the distribution of radiances in the aureole region (Aoki and Fujiyoshi, 2003). In the present study, we analyzed a set of measurements of the direct solar irradiance and the solar aureole radiance distributions within $160^{\circ}$ of the center of the Sun. The measurements were made in $30 \mathrm{~s}$ to $2 \mathrm{~min}$, depending on SZA, and were repeated every $5 \mathrm{~min}$. The $\tau$ values at $400,500,675,870$, and $1020 \mathrm{~nm}$ were derived using the inversion algorithm (SKYRAD.pack, version 4.2) developed by Nakajima et al. (1996). The error in $\tau$ was generally as small as $\sim 0.01$ (Kim et al., 2005), comparable to Sun photometer measurements implemented in AERONET. Only $30 \%$ of the data are used below to minimize the influence by cloud contamination (Aoki and Fujiyoshi, 2003). The Ångström exponent was calculated from the above five $\tau$ values and was used to derive $\tau$ at $476 \mathrm{~nm}$.

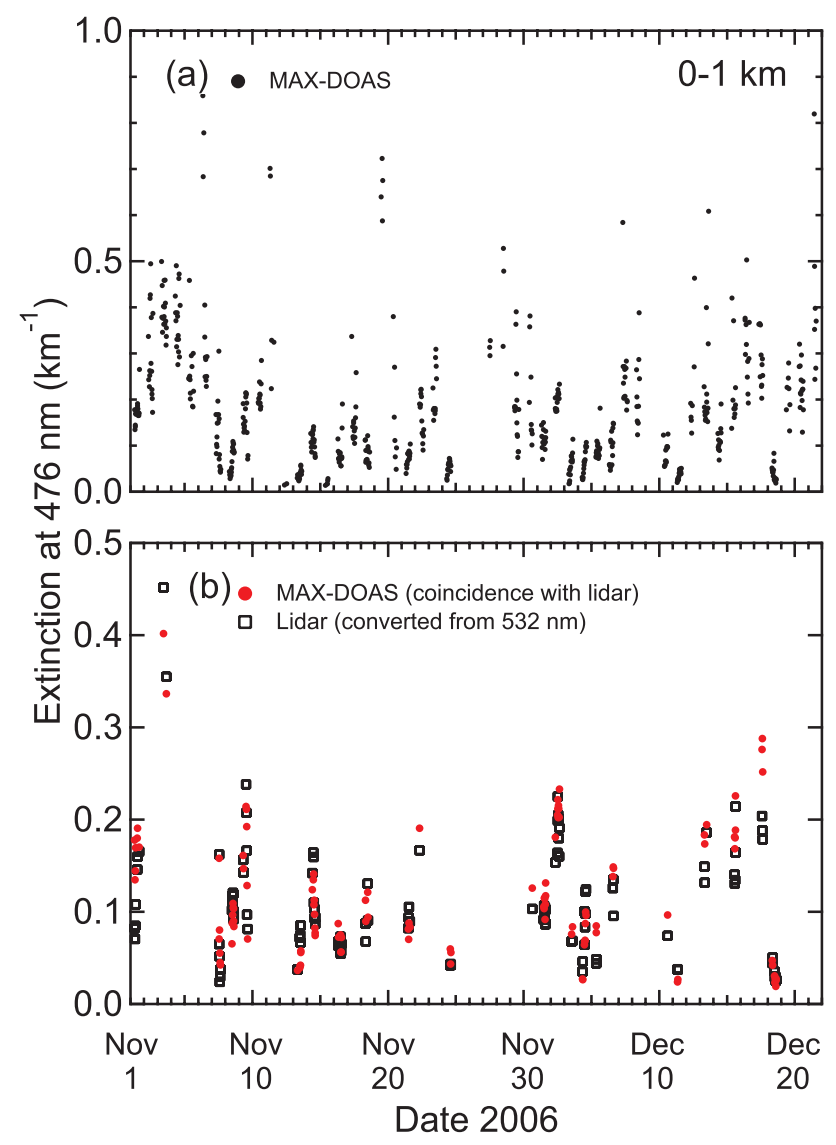

Fig. 7. (a) Time series of all the MAX-DOAS aerosol extinction coefficient $(k)$ data at $476 \mathrm{~nm}$ for the layer from 0 to $1 \mathrm{~km}$. (b) Only coincident MAX-DOAS (red) and lidar (black) data are shown. Original lidar data have been converted to the values at $476 \mathrm{~nm}$ using the Ångström exponent derived from sky radiometer data.

\section{Results and discussion}

Figure 7a shows the time series of all the MAX-DOAS $k(0-$ $1 \mathrm{~km})$ values at $476 \mathrm{~nm}$ from 1 November to 21 December 2006. The value of $k(0-1 \mathrm{~km})$ represents the mean value of $k$ in the layer from 0 to $1 \mathrm{~km}$, as defined earlier. In Figs. $7 \mathrm{~b}$ and 8, only coincident pairs of MAX-DOAS (red) and lidar (black) data are plotted. Note that the coincident pairs have been selected using cloud-free lidar data, providing favorable comparison conditions. However, this does not necessarily mean that no clouds occurred at the MAX-DOAS viewing directions. It can readily be seen from Figs. $7 \mathrm{~b}$ and 8 that the MAX-DOAS $k(0-1 \mathrm{~km})$ values show temporal variations very similar to the lidar data. The correlations between MAX-DOAS and lidar $k(0-1 \mathrm{~km})$ values are compact (slope $=1.01$ and correlation coefficient $R^{2}=0.85$ ), and in most cases the differences are less than 30\% (Fig. 9a).

As mentioned above, the lidar data have an uncertainty of more than $30 \%$, due to the use of a fixed $S$ ratio. In addition, MAX-DOAS and lidar measurements were made with 


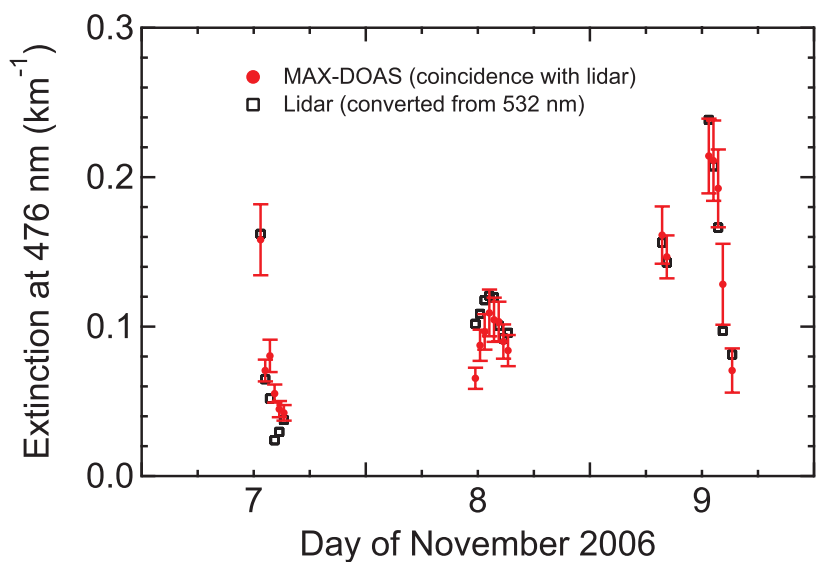

Fig. 8. Same as Fig. 7, but for the comparisons only for 7-9 November 2006. 6 November is omitted, because of no coincident measurements. Error bars represent errors estimated from the retrieval covariance matrix.

different geometries (the combination of zenith-sky and offaxis versus zenith-sky only, respectively) and different integration times for completing a set of measurements (30 versus $5 \mathrm{~min}$, respectively). Because these factors should explain at least part of the differences seen in Fig. 9a, the overall intrinsic uncertainties of MAX-DOAS $k(0-1 \mathrm{~km})$ are smaller than $30 \%$. Similarly, the uncertainty of the $k(1-2 \mathrm{~km})$ values was estimated from the comparisons with lidar data (Fig. 9b) to be less than $60 \%$. These agreements may indicate that the vertical resolution at altitudes below $2 \mathrm{~km}$ was roughly $1 \mathrm{~km}$, corresponding to the vertical spacing chosen in the parameterization of $k$, consistent with the simulation done by Frie $\beta$ et al. (2006). MAX-DOAS and lidar $k(2-3 \mathrm{~km})$ values were both about $0.02 \mathrm{~km}^{-1}$. However, it was difficult to assess the MAX-DOAS $k(2-3 \mathrm{~km})$ values, because the values were very close to the a priori value used in the MAX-DOAS retrieval.

It is interesting to note that these comparisons have been made without detailed cloud screening methods for the MAX-DOAS data, and it is very likely that some clouds were occasionally near the FOVs of the MAX-DOAS system, as mentioned above. In the MAX-DOAS/lidar comparisons of $k$ for the 0-1 km (1-2 km) layer shown in Fig. 9, however, no significant differences exceeding 30\% (60\%) are generally seen, suggesting that uncertainties due to such cloud influences were less than $30 \%$ (60\%).

We next compare $\tau$ values from MAX-DOAS and the sky radiometer (Fig. 10). Also plotted in Figs. 10b and 11 are the mean values of the Moderate Resolution Imaging Spectrometer (MODIS) data (collection 5) obtained within $0.3^{\circ}$ latitude and longitude of the measurement site. Two MODIS datasets from different satellites (Terra and Aqua) have been averaged separately but are plotted with the same symbols for simplicity. The MODIS data with a cloud fraction less than 0.2 were used. The original MODIS $\tau$ values at $470 \mathrm{~nm}$ have

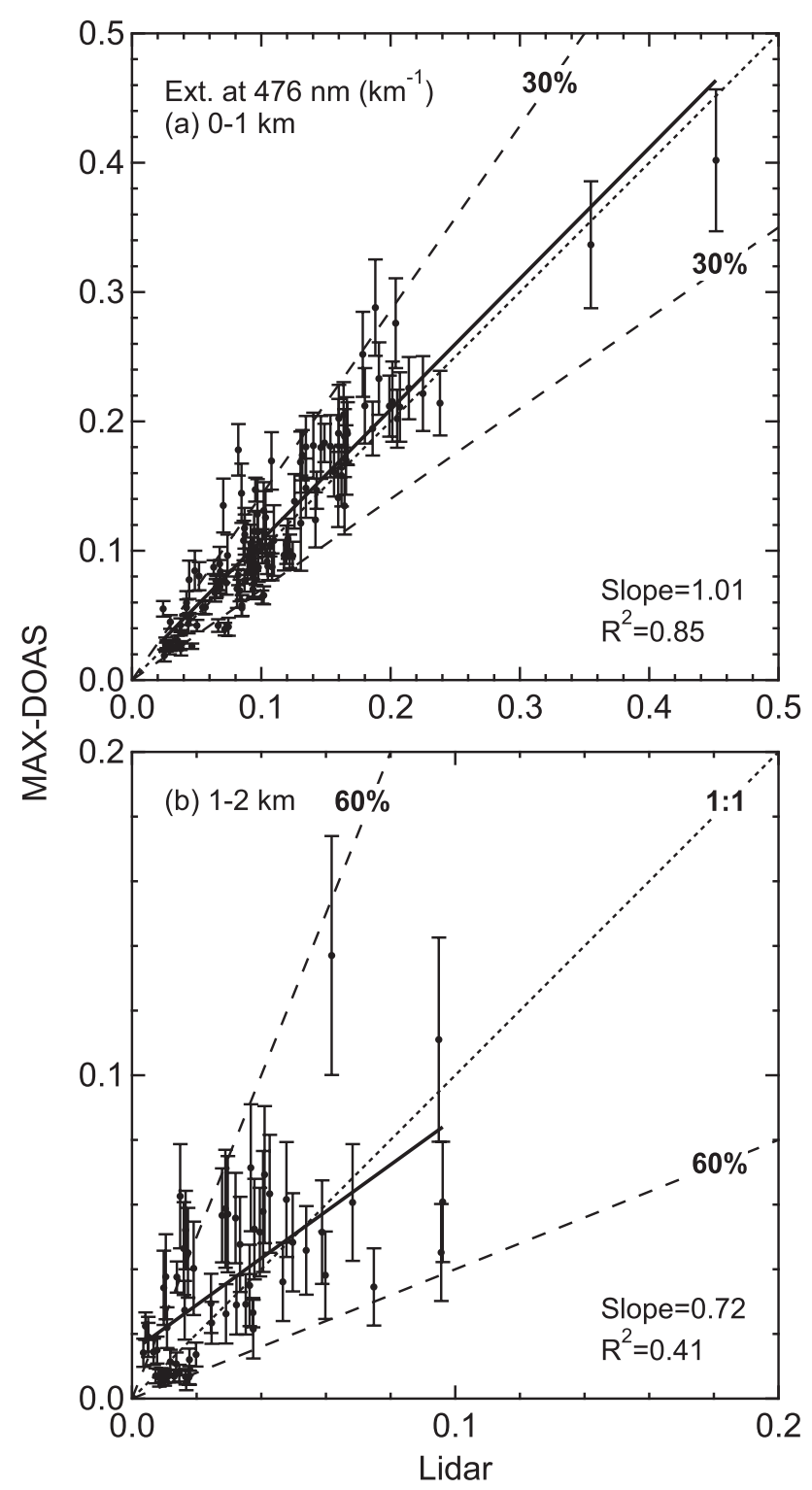

Fig. 9. Correlations between $k$ values from MAX-DOAS and lidar for layers of (a) 0-1 and (b) 1-2 km. The 1:1 relationship and the $30 \%$ range are represented by the dotted line and dashed lines, respectively. Error bars represent errors estimated from the retrieval covariance matrix.

been converted to those at $476 \mathrm{~nm}$ using MODIS Ångström exponent data. Good general agreement between the three datasets can be seen in Figs. 10b and 11.

The correlations between MAX-DOAS and sky radiometer data are shown in Fig. 12. For most cases the agreement is within 30\% (Fig. 12). However, MAX-DOAS values tend to be smaller than sky radiometer values at sky radiometer $\tau$ values greater than 0.4 (Fig. 12).

As the sky radiometer tracked the Sun, it was oriented mainly toward the east-south-west sky, whereas the 


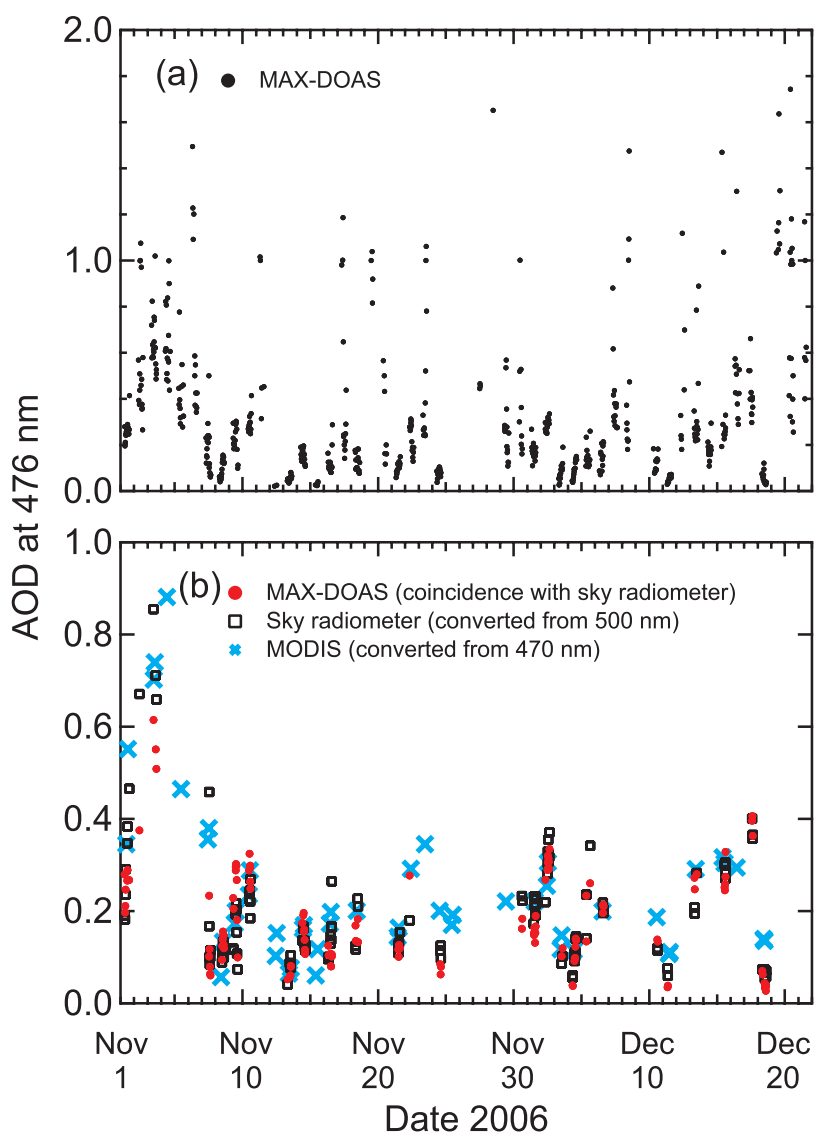

Fig. 10. (a) Time series of all the MAX-DOAS $\tau$ (AOD) data at $476 \mathrm{~nm}$. (b) Only coincident MAX-DOAS (red) and sky radiometer (black) data are shown. For reference, MODIS $\tau$ data (sky blue) are also plotted. The original sky radiometer and MODIS data have been converted to the values at $476 \mathrm{~nm}$ using the Ångström exponent.

MAX-DOAS measured the sky in a different direction (northwest). In addition, measurements by the sky radiometer were made for an integration time of $30 \mathrm{~s}$ to $2 \mathrm{~min}$, which was different than that of MAX-DOAS (30 min). Therefore, the $\tau$ values in air masses measured by MAX-DOAS and the sky radiometer should have occasionally been different.

These influences of the incomplete matching of the measured air masses might explain the differences between MAX-DOAS and sky radiometer data. It is unlikely, however, that these influences are the dominant factor causing the systematic differences seen at sky radiometer $\tau$ values greater than 0.4 , which are expected to show random features in the differences.

A simulation of MAX-DOAS aerosol measurements by Frieß et al. (2006) has shown that the sensitivity of the measurements decreases with increasing altitude in the troposphere. This is supported by the averaging kernels for our MAX-DOAS aerosol retrievals (Fig. 4). As discussed above, the profiles of $k$ from MAX-DOAS agreed well with those

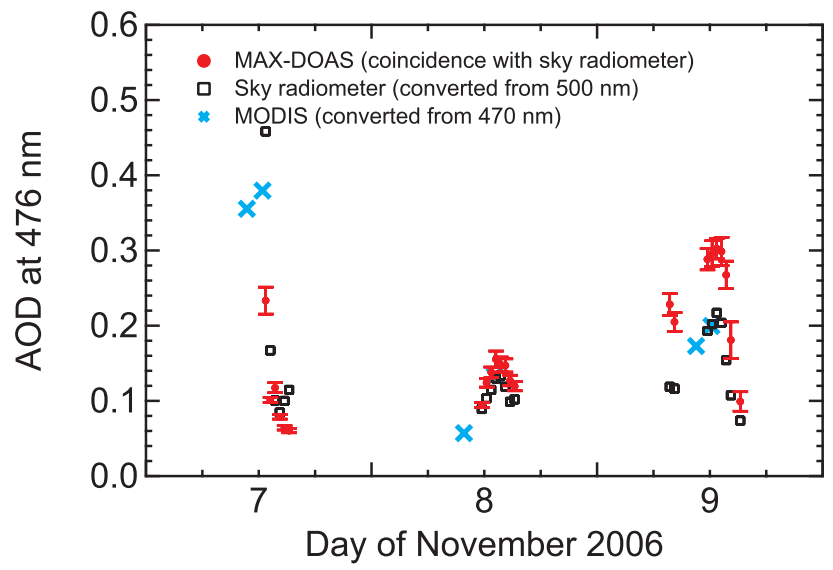

Fig. 11. Same as Fig. 10, but for the comparisons only for 7-9 November 2006. 6 November is omitted, because of no coincident measurements. Error bars represent the errors estimated from the retrieval covariance matrix.

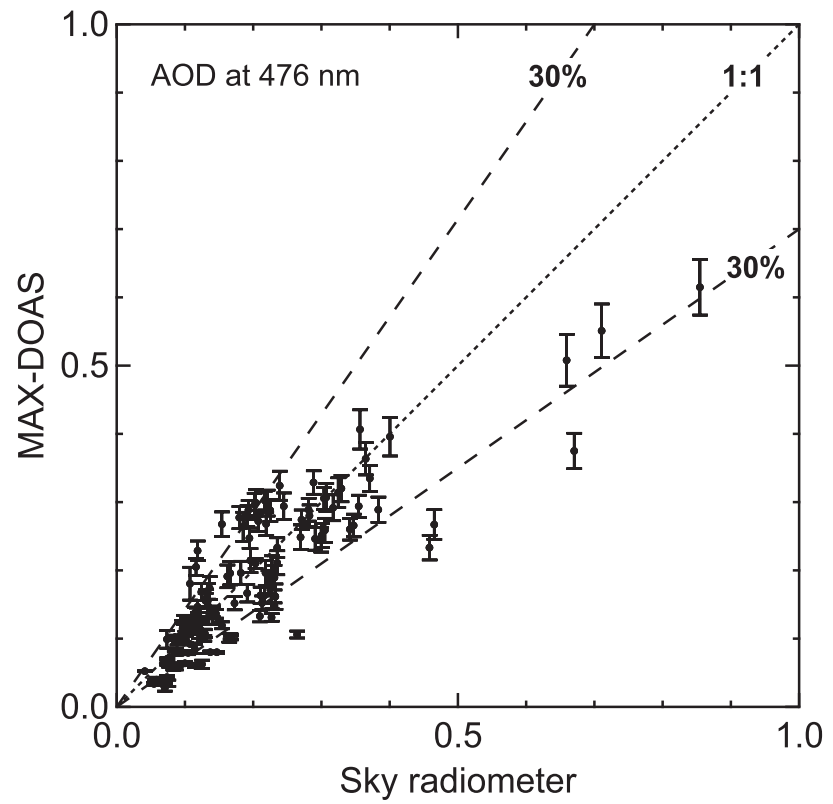

Fig. 12. Same as Fig. 9, but for the correlations between $\tau$ (AOD) values at $476 \mathrm{~nm}$ from MAX-DOAS and sky radiometer data. Error bars represent the errors estimated from the retrieval covariance matrix.

from the lidar for altitudes below $3 \mathrm{~km}$. Therefore, an underestimate of the MAX-DOAS $\tau$ values might have occurred, owing to optically thick aerosols above $3 \mathrm{~km}$. This will be confirmed in the future by investigating other sites and seasons, where and when optically thick aerosols occur more often at high altitudes.

Another possible cause is the cloud influence. To quantify the maximum influence of clouds on the MAXDOAS retrievals, an additional sensitivity test was performed 
assuming that all extinction occurred by clouds with $g=0.86$ and $s=1.00$. The sensitivity test showed that MAX-DOAS $\tau$ values ( $k$ below $2 \mathrm{~km}$ ) retrieved assuming typical aerosols ( $g=0.65, s=0.95)$ were systematically smaller than those retrieved assuming clouds by about $30 \%$ (40\%). This result suggests that for more realistic situations containing both aerosols and clouds, the $\tau$ value ( $k$ below $2 \mathrm{~km}$ ) retrieved assuming typical aerosols includes the 30\%-(40\%) reduced contribution of the cloud optical depth, possibly explaining part of the systematic differences seen in the comparisons between MAX-DOAS and sky radiometer $\tau$ data. In addition, this non-negligible cloud influence qualitatively explains why MAX-DOAS data showed occasional enhancements of $\tau$ values when no coincidences with sky radiometer measurements under cloud-free conditions occurred (Fig. 10).

Considering the above results suggesting the reduced cloud contribution, the simulation performed by Frieß et al. (2006), and the averaging kernels for our retrieval method, MAX-DOAS measurements would be very insensitive to high-altitude clouds, suggesting that $k$ profiles in the lower troposphere can be measured even when clouds are present at high altitudes. While MAX-DOAS has these advantages, the development of a proper cloud screening method will improve the performance of aerosol measurements by MAX-DOAS, as well as other remote sensing techniques for aerosol measurements.

\section{Conclusions}

We have presented, for the first time, a new aerosol retrieval algorithm applicable to MAX-DOAS measurements made in the real atmosphere. To characterize the retrieval algorithm for deriving $\tau$ and the vertical profile of $k$ at $476 \mathrm{~nm}$ in the lower troposphere, we performed MAX-DOAS measurements at Tsukuba, Japan, from 1 November to 21 December 2006, and compared them with lidar and sky radiometer measurements. The comparisons between $k(0-1 \mathrm{~km})$ values from MAX-DOAS and the lidar showed good agreement, within $30 \%$ for most cases, although the cases compared probably included partly cloudy conditions. Considering that errors in lidar $k$ data could occasionally exceed $30 \%$, it is likely that the comparisons yielded an upper limit to the overall uncertainty of MAX-DOAS $k(0-1 \mathrm{~km})$ data. Similarly, the overall uncertainty of MAX-DOAS $k(1-2 \mathrm{~km})$ was estimated to be less than $60 \%$. The MAX-DOAS $\tau$ values generally agreed with sky radiometer data to within $30 \%$. Thus, by applying our aerosol retrieval algorithm, MAX-DOAS provides a new, reliable dataset of aerosols in the troposphere. Moreover, the derived aerosol properties can be used as reliable input parameters for the vertical profile retrieval of trace gases detected by MAX-DOAS. In some cases, however, the MAXDOAS $\tau$ values tended to be smaller than sky radiometer data. This underestimation likely occurred when optically thick aerosols were present at high altitudes and/or clouds occurred in the lower troposphere. It was suggested that $k$ profiles can be measured by MAX-DOAS even when clouds are present at high altitudes. However, the development of a proper cloud screening method is highly desirable for more accurate aerosol measurements by MAX-DOAS.

Acknowledgements. The authors thank T. Wagner for providing absorption cross section data. We are grateful to $\mathrm{K}$. Chance for providing the Ring calculation model. MODIS data were obtained from the NASA LAADS web site. This work was supported by Global Environment Research fund (B-051) and Japan EOS Promotion Program (JEPP).

Edited by: R. Volkamer

\section{References}

Aoki, K. and Fujiyoshi, Y.: Sky radiometer measurements of aerosol optical properties over Sapporo, Japan, J. Meteorol. Soc. Jpn., 81, 3, 493-513, 2003.

Aliwell, S. R., van Roozendael, M., Johnston, P. V., Richter, A., Wagner, T., Arlander, D. W., Burrows, J. P., Fish, D. J., Jones, R. L., Tørnkvist, K. K., Lambert, J.-C., Pfeilsticker, K., and Pundt, I.: Analysis for $\mathrm{BrO}$ in zenith-sky spectra: An intercomparison exercise for analysis improvement, J. Geophys. Res., 107, D14, 4199, doi:10.1029/2001JD000329, 2002.

Bogumil, K., Orphal, J., Homann, T., Voigt, S., Spietz, P., Fleischmann, O. C., Vogel, A., Hartmann, M., Bovensmann, H., Frerik, J., and Burrows, J. P.: Measurements of molecular absorption spectra with the SCIAMACHY pre-flight model: Instrument characterization and reference data for atmospheric remotesensing in the $230-2380 \mathrm{~nm}$ region, J. Photoch. Photobio. A., 157, 167-184, 2003.

Cattrall, C., Reagan, J., Thome, K., and Dubovik, O.: Variability of aerosol and spectral lidar and backscatter and extinction ratios of key aerosol types derived from selected Aerosol Robotic Network locations, J. Geophys. Res., 110, D10S11, doi:10.1029/2004JD005124, 2005.

Chance, K. and Spurr, R. J. D.: Ring effect studies: Rayleigh scattering, including molecular parameters for rotational Raman scattering, and the Fraunhofer spectrum, Appl. Optics, 36, 52245230, 1997.

Chance, K., Kurosu, T. P., and Sioris, C. E.: Undersampling correction for array detector-based satellite spectrometers, Appl. Optics., 44, 7, 1296-1304, 2005.

Fernald, F. G.: Analysis of atmospheric lidar observations: some comments, Appl. Optics, 23, 5, 652-653, 1984.

Frie $\beta$, U., Monks, P. S., Remedios, J. J., Rozanov, A., Sinreich, R., Wagner, T., and Platt, U.: MAX-DOAS $\mathrm{O}_{4}$ measurements: A new technique to derive information on atmospheric aerosols: 2. Modeling studies, J. Geophys. Res., 111, D14203, doi:10.1029/2005JD006618, 2006.

Grainger, J. F. and Ring, J.: Anomalous Fraunhofer line profiles, Nature, 193, 762, 1962.

Greenblatt, G. D., Orlando, J. J., Burkholder, J. B., and Ravishankara, A. R.: Absorption measurements of oxygen between 330 and 1140 nm, J. Geophys. Res., 95, 11, 18 577-18 582, 1990. 
Heckel, A., Richter, A., Tarsu, T., Wittrock, F., Hak, C., Pundt, I., Junkermann, W., and Burrows, J. P.: MAX-DOAS measurements of formaldehyde in the Po-Valley, Atmos. Chem. Phys., 5, 909918, 2005, http://www.atmos-chem-phys.net/5/909/2005/.

Hendrick, F., van Roozendael, M., Kylling, A., Petritoli, A., Rozanov, A., Sanghavi, S., Schofield, R., von Friedeburg, C., Wagner, T., Wittrock, F., Fonteyn, D., and De Mazière, M.: Intercomparison exercise between different radiative transfer models used for the interpretation of ground-based zenith-sky and multiaxis DOAS observations, Atmos. Chem. Phys., 6, 93-108, 2006, http://www.atmos-chem-phys.net/6/93/2006/.

Hönninger, G., von Friedeburg, C., and Platt, U.: Multi axis differential optical absorption spectroscopy (MAX-DOAS), Atmos. Chem. Phys., 4, 231-254, 2004,

http://www.atmos-chem-phys.net/4/231/2004/.

Iwabuchi, H.: Efficient Monte Carlo methods for radiative transfer modeling, J. Atmos. Sci., 63, 9, 2324-2339, 2006.

Kaufman, Y. J., Tanré, D., and Boucher, O.: A satellite view of aerosols in the climate system, Rev. Nature, 419, 215-223, 2002.

Kim, D.-H., Sohn, B. J., Nakajima, T., and Takamura, T.: Aerosol radiative forcing over east Asia determined from ground-based solar radiation measurements, J. Geophys. Res., 110, D10S22, doi:10.1029/2004JD004678, 2005.

Kurucz, R. L., Furenlid, I., Brault, J., and Testerman, L.: Solar flux atlas from 296 to $1300 \mathrm{~nm}$, Natl. Sol. Obs., Sunspot, New Mexico, 240 pp, 1984

Leigh, R. J., Corlett, G. K., Frie $\beta$, U., and Monks, P. S.: Concurrent multiaxis differential optical absorption spectroscopy system for the measurement of tropospheric nitrogen dioxide, Appl. Optics, 45, 28, 7504-7518, 2006.

Liu, X., Chance, K., Sioris, C. E., Spurr, R. J. D., Kurosu, T. P., and Martin, R. V.: Ozone profile and tropospheric ozone retrievals from the Global Ozone Monitoring Experiment: Algorithm description and validation, J. Geophys. Res., 110, D20307, doi:10.1029/2005JD006240, 2005.

Marchuk, G., Mikhailov, G., Nazaraliev, M., Darbinjan, R., Kargin, B., and Elepov, B.: The Monte Carlo Methods in Atmospheric Optics, Springer-Verlag Berlin, 208 pp, 1980.

Nakajima, T., Tonna, G., Rao, R., Boi, P., Kaufman, Y., and Holben, B.: Use of sky brightness measurements from ground for remote sensing of particulate polydispersions, Appl. Optics, 35, 15, 2672-2686, 1996.

Platt, U.: Differential optical absorption spectroscopy (DOAS), Air Monitoring by Spectroscopic Techniques, 127, 27-84, edited by M. W. Sigrist, John Wiley\&Sons, Inc., New York, 1994.

Rodgers, C. D.: Inverse methods for atmospheric sounding: Theory and practice, Ser. Atmos. Oceanic Planet. Phys., 2, edited by F. W. Taylor, World Sci., Hackensack, N. J., 2000.

Rothman, L. S., Barbe, A., Benner, D. C., Brown, L. R., CamyPeyret, C., Carleer, M. R., Chance, K., Clerbaux, C., Dana, V., Devi, V. M., Fayt, A., Flaud, J.-M., Gamache, R. R., Goldman, A., Jacquemart, D., Jucks, K. W., Lafferty, W. J., Mandin, J.-Y., Massie, S. T., Nemtchinov, V., Newnham, D. A., Perrin, A., Rinsland, C. P., Schroeder, J., Smith, K. M., Smith, M. A. H, Tang, K., Toth, R. A., Vander Auwera, J., Varanasi, P., and Yoshino, K.: The HITRAN molecular spectroscopic database: edition of 2000 including updates through 2001, J. Quant. Spectrosc. Ra., $82,5-44,2003$.
Shimizu, A., Sugimoto, N., Matsui, I., Arao, K., Uno, I., Murayama, T., Kagawa, N., Aoki, K., Uchiyama, A., and Yamazaki, A.: Continuous observations of Asian dust and other aerosols by polarization lidars in China and Japan during ACE-Asia, J. Geophys. Res., 109, D19S17, doi:10.1029/2002JD003253, 2004

Sinreich, R., Volkamer, R., Filsinger, F., Frie $\beta$, U., Kern, C., Platt, U., Sebastián, O., and Wagner, T.: MAX-DOAS detection of glyoxal during ICARTT 2004, Atmos. Chem. Phys., 7, 1293-1303, 2007, http://www.atmos-chem-phys.net/7/1293/2007/.

Tatarov, B., Sugimoto, N., Matsui, I., and Shimizu, A.: Two-yearobservations of optical properties of the tropospheric aerosol and clouds by a high-spectral-resolution lidar over Tsukuba, Japan, Reviewed and Revised Papers Presented at the 23rd International Laser Radar Conference, 23ILRC, ISBN 4-9902916-0-3, 451454, 2006.

Vandaele, A. C., Hermans, C., Simon, P. C., Carleer, M., Colin, R., Fally, S., Mérienne, M. F., Jenouvrier, A., and Coquart, B.: Measurements of the $\mathrm{NO}_{2}$ absorption cross-section from $42000 \mathrm{~cm}^{-1}$ to $10000 \mathrm{~cm}^{-1}(238-1000 \mathrm{~nm})$ at $220 \mathrm{~K}$ and 294 K, J. Quant. Spectrosc. Ra., 59, 171-184, 1998.

Wagner, T., Dix, B., von Friedeburg, C., Frieß, U., Sanghavi, S., Sinreich, R., and Platt, U.: MAX-DOAS $\mathrm{O}_{4}$ measurements: A new technique to derive information on atmospheric aerosols - Principles and information content, J. Geophys. Res., 109, D22205, doi:10.1029/2004JD004904, 2004.

Wagner, T., Burrows, J. P., Deutschmann, T., Dix, B., von Friedeburg, C., Frieß, U., Hendrick, F., Heue, K.-P., Irie, H., Iwabuchi, H., Kanaya, Y., Keller, J., McLinden, C. A., Oetjen, H., Palazzi, E., Petritoli, A., Platt, U., Postylyakov, O., Pukite, J., Richter, A., van Roozendael, M., Rozanov, A., Rozanov, V., Sinreich, R., Sanghavi, S., and Wittrock, F.: Comparison of box-airmass-factors and radiances for multiple-axis differential optical absorption spectroscopy (MAX-DOAS) geometries calculated from different UV/visible radiative transfer models, Atmos. Chem. Phys., 7, 1809-1833, 2007,

http://www.atmos-chem-phys.net/7/1809/2007/.

Wittrock, F., Oetjen, H., Richter, A., Fietkau, S., Medeke, T., Rozanov, A., and Burrows, J. P.: MAX-DOAS measurements of atmospheric trace gases in Ny-Ålesund - Radiative transfer studies and their application, Atmos. Chem. Phys., 4, 955-966, 2004, http://www.atmos-chem-phys.net/4/955/2004/. 